\title{
How Different Government Subsidy Objects Impact on Green Supply Chain Decision considering Consumer Group Complexity
}

\author{
Qingfeng Meng $\mathbb{D},{ }^{1}$ Mengwan Li, ${ }^{1}$ Zhen Li $\mathbb{D},{ }^{1}$ and Jing $\mathrm{Zhu}^{2}$ \\ ${ }^{1}$ School of Management, Jiangsu University, Zhenjiang 212013, China \\ ${ }^{2}$ School of Management and Humanities, Jiangsu University Jingjiang College, Zhenjiang 212000, China \\ Correspondence should be addressed to Zhen Li; janeli@ujs.edu.cn
}

Received 29 November 2019; Accepted 15 April 2020; Published 4 May 2020

Academic Editor: Zhen-Lai Han

Copyright (C) 2020 Qingfeng Meng et al. This is an open access article distributed under the Creative Commons Attribution License, which permits unrestricted use, distribution, and reproduction in any medium, provided the original work is properly cited.

\begin{abstract}
This paper fully considers the complexity characteristics of the consumer group, such as the heterogeneity of consumer environmental preferences and consumption levels and constructs a two-stage price decision model of green supply chain composed of the manufacturer and retailers. Under the four different scenarios, no government subsidies, government subsidies are given to the manufacturer, government subsidies are given to the green product retailer, and government subsidies are given to green product consumers, the impact of government subsidies on green supply chain member price decisions is analyzed, and the validity of the model is verified by an example. The results show that compared with the no government subsidies, government subsidies to the manufacturer will reduce the wholesale and sales prices of green products, and subsidies to the green product retailer will lead to higher wholesale prices and lower sales prices of green products, and subsidies to green product consumers will increase the wholesale and sales prices of green products. No matter which object is subsidized by the government, the wholesale price of general products will not change and the sales price will decrease. Government subsidies will facilitate the sales of green products, thereby expanding the market share of green products.
\end{abstract}

\section{Introduction}

With the advancement of science and technology and the development of the economy, resources on the planet are becoming increasingly scarce, and environmental pollution is further intensifying. In this context, the development of green technology and the promotion of green products have become particularly important. However, although the benefits of green development in reducing pollution are obvious, most green technologies require a large amount of up-front capital, which leads to an increase in production costs, which will reduce the incentives for green production [1]. Therefore, in order to promote green development, reduce pollution, and protect the environment, it is particularly important for the government to implement some green development incentives [2]. For example, in May 2012, the State Council of China announced that it would allocate 26.5 billion yuan to subsidize energy-saving appliances for one year, mainly covering five categories of household appliances: flat-panel TVs, refrigerators, air conditioners, washing machines, and water heaters [3]. In 2015, the Ministry of Finance of China issued the "Notice on the Financial Support Policy for the Promotion and Application of New Energy Vehicles in 2016-2020," which provides certain subsidies to consumers who purchase new energy vehicles. In 2018, the Ministry of Finance of China officially issued the "Notice on Adjusting and Improving the Financial Subsidy Policy for the Promotion and Application of New Energy Vehicles," and made corresponding adjustments to the subsidy policy for new energy vehicles. The implementation of these subsidy policies has greatly promoted the green development of the supply chain.

As an important factor to be considered in supply chain decision-making, government subsidies have an important impact on the operation of the supply chain. In recent years, many scholars have conducted in-depth and extensive 
research on the impact of government subsidy supply chain members on green supply chain decision-making. Firstly, in terms of the impact of government subsidized manufacturer on green supply chain decisions, Yang and Xiao [4] constructed three game models of the green supply chain for the government subsidized manufacturer under the conditions of fuzzy uncertainty in manufacturing costs and consumer demand. Xue et al. [5] studied the impact of the government subsidized manufacturer on retail prices, energy efficiency, market demand, supply chain profits, and social welfare for energy-saving products. The results showed that government subsidies can significantly improve social welfare levels and promote the improvement of energy-saving products. Zhuo and Wei [6] analyzed the incentive effect and green lower limit in the case of government subsidized manufacturers, based on the characteristics of uncertainty in the consumer market. Zhan et al. [7] studied the decisionmaking issues of the manufacturer and retailer in a decentralized and centralized decision-making model under the scenario of government subsidized manufacturers and increased environmental awareness of the consumer. Yu et al. [8] established an optimization model that considers green preferences and government subsidized manufacturers with the goal of maximizing manufacturers' profits. Guo et al. [9] explored the impact of the government subsidized manufacturer on social welfare and the profits of supply chain members.

Secondly, the influence of government subsidized consumers on green supply chain decision-making has also attracted the attention of many scholars. Chemama et al. [10] examined governments use consumer subsidies to promote green technologies and how policy adjustments over time will interact with industry production decisions. Cohen et al. [11] analyzed the government's interaction with the supplier when designing consumer subsidy policies and the impact of demand uncertainty on each participant in designing strategies. He et al. [12] explored the channel structure and pricing decisions of the manufacturer and the government's consumer subsidy policy for purchasing remanufactured products. Huang et al. [13] analyzed the fuel vehicle supply chain and power and fuel vehicle supply chain in the duopoly environment; the government implements a subsidized consumer incentive plan to promote the sales of electric vehicles, and the results show that, with the strong bargaining power of consumers, government subsidies can increase the sales of electric vehicles more effectively. Li et al. [14] studied the strategy of government subsidies to consumers, analyzed the impact of consumption subsidy, and replaced the subsidy on environmentally friendly products in the dual-channel supply chain. Ma et al. [15] studied the impact of subsidized consumers on the dual-channel closedloop supply chain. Based on the introduction of the government consumption subsidy program and the dualchannel closed-loop supply chain, the decision of the channel members before and after the performance of the government-funded plan is analyzed.

The abovementioned studies are more concerned with government subsidies for a single, specific supply chain member, but there is less literature to analyze and compare the impact of government subsidy on green supply chain member decisions in different object subsidy scenarios. In addition, in the scenario of government subsidies for different objects, it is less common to consider the impact of consumer group complexity on the decision-making of green supply chain members. This paper mainly considers two aspects of the complexity of the consumer group: one is the heterogeneity of consumer environmental preferences, and the other is the heterogeneity of consumer consumption levels. Based on the abovementioned analysis, this paper constructs a two-stage game model of the manufacturer, general product retailer, and green product retailer from the perspective of the green supply chain, with the manufacturer and retailers as research objects. On the basis of fully considering the complexity characteristics of consumer groups, this paper studies the influence of government subsidies to different objects on the price decision-making of members of the green supply chain. This paper considers the heterogeneity of consumer environmental preferences and the heterogeneity of consumption levels into the market demand of green products, studies the impact of government subsidies on green supply chain member price decisions in four different scenarios, including no government subsidies, government subsidies given to the manufacturer, government subsidies given to the green product retailer, and government subsidies given to green product consumers, and compares product price decisions, sales volume, and profits under different subsidy scenarios. The aim is to provide a theoretical basis for promoting the development of green supply chains.

Compared with the existing research, this paper has the following innovations and expansions.

Firstly, most of the existing studies consider the scenario of government subsidies to single object, and this paper considers four different scenarios: no government subsidies, government subsidies given to the manufacturer, government subsidies given to the green product retailer, and government subsidies given to the green product consumers. It separately analyzes and compares the wholesale prices, sales prices, sales volume, and profits of various companies and the changes brought by government subsidies to the price decision of green supply chain members in four different scenarios.

Secondly, for four different scenarios, this paper takes the heterogeneity of consumers' environmental preference and consumption level into consideration in the price decision of the green supply chain. In the research process, the complexity characteristics of consumer groups and their impact on the decision-making of the green supply chain are fully considered, making the model more realistic.

\section{Problem Description and Conditional Assumptions}

This paper studies a secondary supply chain consisting of a manufacturer, a general product retailer, and a green product retailer. The green supply chain structure is shown in Figure 1. The manufacturer, general product retailer, and green product retailer are represented by $M, R_{1}$, and $R_{2}$, 
respectively. The manufacturer produces general products and green products, the general product retailer sells general products, and the green product retailer sells green products. Assume that the production cost of unit general product and unit green product is $c_{n}$ and $c_{g}$, respectively. Since the production of green products requires a large amount of green technology, it is assumed that $c_{g}>c_{n}$.

In order to promote the development of green supply chains, $s$ indicates the government's subsidy quota for each unit of green products. Assume that there are three ways for the government to subsidize green products, one of which is to subsidize the manufacturer, one is to subsidize the green product retailer, and the other is to subsidize green product consumers. $o$ means the scenario of no government subsidies, $m$ means the scenario of government subsidies are given to the manufacturer, $r$ means the scenario of government subsidies are given to the green product retailer, and $c$ means the scenario of government subsidies are given to green product consumers. Assuming that the manufacturer is dominant in the market, retailers are subordinate.

Assume that the wholesale price of the unit general product and the unit green product is $\omega_{n}^{i}$ and $\omega_{g}^{i}$, respectively, the sales price is $p_{n}^{i}$ and $p_{g}^{i}$, and the sales volume is $q_{n}^{i}$ and $q_{g}^{i}$, respectively. $\pi_{M}^{i}, \pi_{R 1}^{i}$, and $\pi_{R 2}^{i}$ represent the profits of the manufacturer, general product retailer, and green product retailer, respectively, where $i$ represents four different subsidy scenarios, $i=\{o, m, r, c\}$.

The complexity of the consumer group in the market is reflected in the two aspects of environmental preference heterogeneity and consumption level heterogeneity, with $\theta$ indicating the consumer's environmental preference coefficient $(\theta>1)$ and $\eta$ indicating the consumer's consumption level coefficient $(\eta>1)$ [16]. Use $V$ to indicate the product utility perceived by the consumer for the unit product and to obey the uniform distribution on $[0,1]$, assuming that the same consumer has the same product utility for the general product and the green product, $\eta V$ indicates consumers' willingness to pay for general products, and $\theta \eta V$ indicates consumers' willingness to pay for green products.

According to the abovementioned assumptions, the consumer surplus of consumers purchasing general products and green products is $U_{n}=\eta V-p_{n}$ and $U_{\mathrm{g}}=\theta \eta V-p_{g}$, respectively. According to the principle of utility maximization, consumers must meet the conditions for purchasing general products:

$$
\frac{p_{n}}{\eta} \leq V \leq \frac{p_{g}-p_{n}}{\eta(\theta-1)}
$$

and consumers must meet the conditions for purchasing green products:

$$
V \geq \max \left\{\frac{p_{g}}{\theta \eta}, \frac{p_{g}-p_{n}}{\eta(\theta-1)}\right\} .
$$

This paper assumes that the market has demand for both general products and green products, so equations (1) and (2) are $\left(p_{n} / \eta\right)<V<\left(\left(p_{g}-p_{n}\right) / \eta(\theta-1)\right), \quad\left(\left(p_{g}-p_{n}\right) / \eta(\theta-\right.$ $1))<V<1$, respectively. The demand function for obtaining the general product and the green product is $q_{n}=$

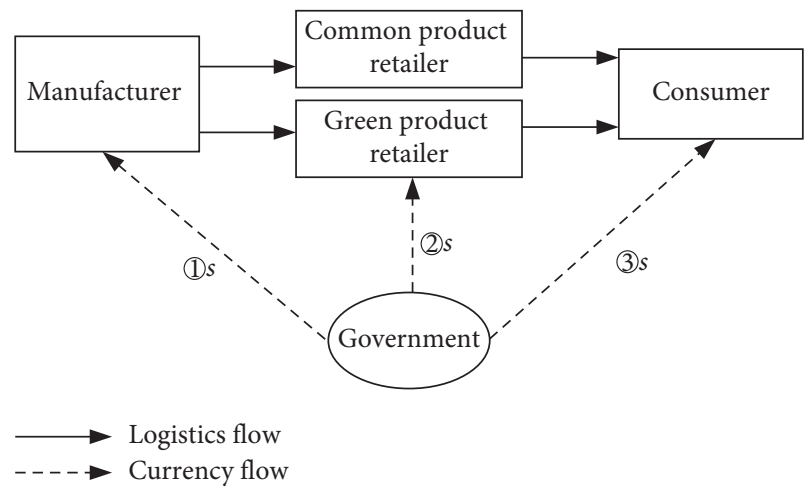

Figure 1: Green supply chain structure framework.

$\left(p_{g}-\theta p_{n}\right) / \eta(\theta-1), \quad q_{g}=1-\left(\left(p_{g}-p_{n}\right) \quad / \eta(\theta-1)\right)$, respectively.

\section{Model Construction and Solution}

3.1. Model of No Government Subsidies. In the absence of government subsidies, the demand functions for general products and green products are

$$
\begin{aligned}
& q_{n}^{o}=\frac{p_{g}^{o}-\theta p_{n}^{o}}{\eta(\theta-1)}, \\
& q_{g}^{o}=1-\frac{p_{g}^{o}-p_{n}^{o}}{\eta(\theta-1)} .
\end{aligned}
$$

According to the supply chain structure and the demand function of general products and green products, the profit functions of the manufacturer, general product retailer, and green product retailer are

$$
\begin{aligned}
& \pi_{M}^{o}=\left(\omega_{n}^{o}-c_{n}\right) q_{n}^{o}+\left(\omega_{g}^{o}-c_{g}\right) q_{g}^{o}, \\
& \pi_{R 1}^{o}=\left(p_{n}^{o}-\omega_{n}^{o}\right) q_{n}^{o}, \\
& \pi_{R 2}^{o}=\left(p_{g}^{o}-\omega_{g}^{o}\right) q_{g}^{o} .
\end{aligned}
$$

Lemma 1. Equations (6) and (7) are concave functions for variables $p_{n}^{o}$ and $p_{g}^{o}$, respectively. Substituting the optimal solutions of equations (6) and (7) into equation (5), it can be concluded that equation (5) is a concave function for variables $\omega_{n}^{o}$ and $\omega_{g}^{o}$.

\section{Proof. See Appendix.}

According to Lemma 1, the price decision, sales volume, and profit of the manufacturer, general product retailer, and green product retailer in the absence of government subsidies are shown in Table 1.

Let $\alpha=-\eta(1-\theta)+c_{g}+(1-2 \theta) c_{n}, \quad \beta=-2 \eta \theta(1-\theta)+$ $(1-2 \theta) c_{q}+\theta c_{n}, \quad X=\left(\left(\theta c_{n}+(1-2 \theta) c_{q}\right) / 2 \theta(1-\theta)\right)$, $Y=\left(\left(2 \theta^{2} c_{n}+(1-3 \theta) c_{g}\right) / \theta(1-\theta)\right)$, and $T=((4 \eta \theta(-1+\theta)$ $\left.\left.+2(1-2 \theta) c_{g}+2 \theta c_{n}\right) /(1-2 \theta)\right)$. 
TABle 1: Price decisions, sales volume, and profit of each member when there is no government subsidy.

\begin{tabular}{lc}
\hline Variable & No government subsidies \\
\hline$\omega_{n_{n}}^{o^{*}}$ & $\left(\eta+c_{n}\right) / 2$ \\
$\omega_{g^{*}}^{o^{*}}$ & $\left(\eta \theta+c_{g}\right) / 2$ \\
$p_{n^{*}}^{o^{*}}$ & $\left(-2 \eta+5 \eta \theta+c_{g}+2 \theta c_{n}\right) /(-2+8 \theta)$ \\
$p_{g}^{o^{*}}$ & $\theta\left(-3 \eta+6 \eta \theta+2 c_{g}+c_{n}\right) /(-2+8 \theta)$ \\
$q_{n^{*}}^{o_{*}}$ & $\theta \alpha /(2 \eta(-1+\theta)(-1+4 \theta))$ \\
$q_{g^{*}}^{o^{*}}$ & $\beta /(2 \eta(-1+\theta)(-1+4 \theta))$ \\
$\pi_{R 1}^{o_{1}}$ & $\theta \alpha^{2} /\left(4 \eta(1-4 \theta)^{2}(-1+\theta)\right)$ \\
$\pi_{R 2}^{o^{*}}$ & $\beta^{2} /\left(4 \eta(1-4 \theta)^{2}(-1+\theta)\right)$ \\
$\pi_{M}^{o^{*}}$ & $\left(\theta\left(\eta-c_{n}\right) \alpha+\left(\eta \theta-c_{g}\right) \beta\right) /(4 \eta(-1+\theta)(-1+4 \theta))$ \\
\hline
\end{tabular}

To ensure that the solution obtained is an effective solution, refer to the constraint $0 \leq q_{\mathrm{g}}<q_{n}$ to obtain Theorem 1 [17].

Theorem 1. Under the condition of no government subsidy, the market competition between general products and green products is as follows:

(1) When $1<\eta \leq X$, the sales volume of green products is 0

(2) When $X<\eta<Y$, there are general products and green products in the market

Proof. See Appendix.

It can be seen from Theorem 1 that when the consumer's consumption level coefficient satisfies $1<\eta \leq X$, the manufacturer will not produce green products, mainly because the consumer's consumption level coefficient is low and consumers do not want to buy high-consumption and high-environmental green products, which leads them to buy low-consumption and low-environmental general products. Therefore, the sales volume of green products is 0 , and the manufacturer will no longer produce green products. When $X<\eta<Y$, the manufacturer produces both general and green products, mainly because the consumer's consumption level is increased and some consumers in the market are willing to buy highconsumption and high-environmental green products. Therefore, the manufacturer will choose to produce both general and green products.

3.2. Model of Government Subsidies to Green Product Manufacturer. When the government subsidizes the manufacturer who produces green products, the profit of the manufacturer producing unit green product is $\omega_{g}^{m}-c_{g}+s$. Therefore, the profit functions of the manufacturer, general product retailer, and green product retailer are

$$
\begin{aligned}
& \pi_{M}^{m}=\left(\omega_{n}^{m}-c_{n}\right) q_{n}^{m}+\left(\omega_{g}^{m}-c_{g}+s\right) q_{g}^{m} \\
& \pi_{R 1}^{m}=\left(p_{n}^{m}-\omega_{n}^{m}\right) q_{n}^{m} \\
& \pi_{R 2}^{m}=\left(p_{g}^{m}-\omega_{g}^{m}\right) q_{g}^{m} .
\end{aligned}
$$

Solving equations (8)-(10), the price decisions, sales volume, and profits of the manufacturer, general product retailer, and green product retailer in the scenario of government subsidized green product manufacturer are shown in Table 2:

Theorem 2. When the government subsidizes the manufacturer of green products, the impact of the government's subsidy quota s on the wholesale price, sales price, and sales volume of green products per unit is as follows:

$$
\begin{aligned}
& \text { (1) }\left(\partial \omega_{n}^{m *} / \partial s\right)=0 \\
& \text { (2) }\left(\partial \omega_{g}^{m *} / \partial s\right)>0 \\
& \text { (3) }\left(\partial p_{n}^{m *} / \partial s\right)<0 \\
& \text { (4) }\left(\partial p_{g}^{m *} / \partial s\right)>0 \\
& \text { (5) }\left(\partial q_{n}^{m *} / \partial s\right)<0 \\
& \text { (6) }\left(\partial q_{g}^{m *} / \partial s\right)>0
\end{aligned}
$$

Proof. See Appendix.

It can be seen from Theorem 2 that, in the scenario of government subsidized manufacturer, the wholesale price and sales price of green products are negatively correlated with the quota of government subsidies and the sales volume is positively related to the quota of government subsidies. The main reason is that, after receiving government subsidies, the manufacturer shares government subsidies with the green product retailer by lowering the wholesale price of green products; the green product retailer attracts consumers to purchase products by reducing the sales price of green products after obtaining shared subsidies, thereby increasing the sales volume of green products. For general products, the wholesale price of general products does not change with the change of subsidy quota and the sales price and sales volume of general products are negatively correlated with the quota of government subsidies. This is because the government subsidized manufacturer leads to a decline in the sales price of green products, and the general product retailer has to lower the sales price of general products to maintain the market share. However, due to lack of financial support, the price cuts are limited and some markets are replaced by green products.

3.3. Model of Government Subsidies to Green Product Retailer. When the government subsidizes the green product retailer, the green product retailer sells unit green products with a profit of $p_{n}^{\mathrm{r}}-\omega_{n}^{r}+s$, so the profit functions of the manufacturer, general product retailer, and green product retailer are

$$
\begin{aligned}
& \pi_{M}^{r}=\left(\omega_{n}^{r}-c_{n}\right) q_{n}^{r}+\left(\omega_{g}^{r}-c_{g}\right) q_{g}^{r}, \\
& \pi_{R 1}^{r}=\left(p_{n}^{r}-\omega_{n}^{r}\right) q_{n}^{r}, \\
& \pi_{R 2}^{r}=\left(p_{g}^{r}-\omega_{g}^{r}+s\right) q_{g}^{r} .
\end{aligned}
$$

Solving equations (11)-(13), the price decisions, sales volume, and profits of the manufacturer, general product 
TABLe 2: Price decision, sales volume, and profit of each member when the government subsidizes the manufacturer.

\begin{tabular}{lc}
\hline Variable & Government subsidies are given to the manufacturer \\
\hline$\omega_{n}^{m *}$ & $\left(\eta+c_{n}\right) / 2$ \\
$\omega_{g}^{m *}$ & $\left(s+\eta \theta+c_{g}\right) / 2$ \\
$p_{n}^{m *}$ & $\left(-s-2 \eta+5 \eta \theta+c_{g}+2 \theta c_{n}\right) /(-2+8 \theta)$ \\
$p_{g}^{m *}$ & $\theta\left(-2 s-3 \eta+6 \eta \theta+2 c_{g}+c_{n}\right) /(-2+8 \theta)$ \\
$q_{n}^{m *}$ & $\theta(-s+\alpha) /(2 \eta(-1+\theta)(-1+4 \theta))$ \\
$q_{g}^{m *}$ & $(-s(1-2 \theta)+\beta) /(2 \eta(-1+\theta)(-1+4 \theta))$ \\
$\pi_{R 1}^{m *}$ & $\theta(-s+\alpha)^{2} /\left(4 \eta(1-4 \theta)^{2}(-1+\theta)\right)$ \\
$\pi_{R 2}^{m *}$ & $(-s(1-2 \theta)+\beta)^{2} /\left(4 \eta(1-4 \theta)^{2}(-1+\theta)\right)$ \\
$\pi_{M}^{m *}$ & $\left(\theta(-s+\alpha)\left(\eta-c_{n}\right)+(s(-1+2 \theta)+\beta)\left(s+\eta \theta-c_{g}\right)\right) /(4 \eta(-1+\theta)(-1+4 \theta))$ \\
\hline
\end{tabular}

retailer, and green product retailer in the scenario of government subsidies to the green product retailer are shown in Table 3:

Theorem 3. When the government subsidizes the green product retailer, the impact of the government's subsidy quota $s$ on the wholesale price, sales price, and sales volume of green products per unit is as follows:

$$
\begin{aligned}
& \text { (1) }\left(\partial \omega_{n}^{r *} / \partial s\right)=0 \\
& \text { (2) }\left(\partial \omega_{g}^{r *} / \partial s\right)>0 \\
& \text { (3) }\left(\partial p_{n}^{r *} / \partial s\right)<0 \\
& \text { (4) }\left(\partial p_{g}^{r *} / \partial s\right)>0 \\
& \text { (5) }\left(\partial q_{n}^{r *} / \partial s\right)<0 \\
& \text { (6) }\left(\partial q_{g}^{r *} / \partial s\right)>0
\end{aligned}
$$

Proof. See Appendix.

It can be seen from Theorem 3 that, in the scenario of government subsidies for the green product retailer, the wholesale price and sales volume of green products are positively related to the quota of government subsidies, and the sales price is negatively related to the quota of government subsidies. This is because when the government subsidizes green product retailer, the manufacturer increases the wholesale price of green products in order to share certain subsidies, and after the green product retailer receives government subsidies, it shares subsidies with consumers by lowering sales prices, thereby the sales volume of green products has gradually improved. Therefore, government subsidizes the green product retailer and has promoted the increase in wholesale price and sales volume of green products and the reduction of sales prices, that is, government subsidizes that the green product retailer can promote the sales of green products. For general products, the impact of government subsidies on the price decisions and sales volume of general products is the same as in the scenario of government subsidizes the manufacturer.

3.4. Model of Government Subsidies to Green Product Consumers. When the government subsidizes green product consumers, the consumer surplus of purchasing general products and green products is $U_{n}=\eta V-p_{n}^{c}$ and $U_{g}=\theta \eta V-p_{g}^{c}+s$, respectively. According to the principle of maximizing utility, when the government subsidizes green product consumers, the demand function of general products and green products is $q_{n}^{c}=\left(p_{g}^{c}-\theta p_{n}^{c}-s\right) / \eta(\theta-1)$ and $q_{g}^{c}=1-\left(p_{g}^{c}-p_{n}^{c}-s\right) / \eta(\theta-1)$, respectively.

When the government subsidizes green product consumers, the profit functions of the manufacturer, general product retailer, and green product retailer are

$$
\begin{aligned}
& \pi_{M}^{c}=\left(\omega_{n}^{c}-c_{n}\right) q_{n}^{c}+\left(\omega_{g}^{c}-c_{g}\right) q_{g}^{c}, \\
& \pi_{R 1}^{c}=\left(p_{n}^{c}-\omega_{n}^{c}\right) q_{n}^{c}, \\
& \pi_{R 2}^{c}=\left(p_{g}^{c}-\omega_{g}^{c}\right) q_{g}^{c} .
\end{aligned}
$$

Solving equations (14)-(16), the price decisions, sales volume, and profits of the manufacturer, general product retailer, and green product retailer in the scenario of government subsidize green product consumers, as shown in Table 4:

Theorem 4. When the government subsidizes green product consumers, the impact of the government's subsidy quota s on the wholesale price, sales price, and sales volume of green products per unit is as follows:

$$
\begin{aligned}
& \text { (1) }\left(\partial \omega_{n}^{c *} / \partial s\right)=0 \\
& \text { (2) }\left(\partial \omega_{g}^{c *} / \partial s\right)>0 \\
& \text { (3) }\left(\partial p_{n}^{c *} / \partial s\right)<0 \\
& \text { (4) }\left(\partial p_{g}^{c *} / \partial s\right)>0 \\
& \text { (5) }\left(\partial q_{n}^{c *} / \partial s\right)<0 \\
& \text { (6) }\left(\partial q_{g}^{c *} / \partial s\right)>0
\end{aligned}
$$

Proof. See Appendix.

It can be seen from Theorem 4 that, in the scenario of government subsidies for green product consumers, the wholesale price, sales price, and sales volume of green products are positively related to government subsidies, and government subsidies increase the wholesale price, sales price, and sales volume of green products. The main reason is that when the government subsidizes green product consumers, the manufacturer and green product retailer increase the wholesale price and sales price of green products in order to share certain subsidies. In addition, since consumers can obtain the corresponding government subsidies for purchasing green products, they can further promote the sales of green products so that the sales volume of green 
TABle 3: Price decision, sales volume, and profit of each member when the government subsidizes the green product retailer.

\begin{tabular}{lc}
\hline Variable & Government subsidies are given to green product retailer \\
\hline$\omega_{n}^{r *}$ & $\left(\eta+c_{n}\right) / 2$ \\
$\omega_{g}^{r *}$ & $\left(s+\eta \theta+c_{g}\right) / 2$ \\
$p_{n}^{r *}$ & $\left(-s-2 \eta+5 \eta \theta+c_{g}+2 \theta c_{n}\right) /(-2+8 \theta)$ \\
$p_{g}^{r *}$ & $\theta\left(-2 s-3 \eta+6 \eta \theta^{2}+2 c_{g}+c_{n}\right) /(-2+8 \theta)$ \\
$q_{n}^{r *}$ & $\theta(-s+\alpha) /(2 \eta(-1+\theta)(-1+4 \theta))$ \\
$q_{g}^{r *}$ & $(-s(1-2 \theta)+\beta) /(2 \eta(-1+\theta)(-1+4 \theta))$ \\
$\pi_{R 1}^{r *}$ & $\theta(-s+\alpha)^{2} /\left(4 \eta(1-4 \theta)^{2}(-1+\theta)\right)$ \\
$\pi_{R 2}^{r *}$ & $(-s(1-2 \theta)+\beta)^{2} /\left(4 \eta(1-4 \theta)^{2}(-1+\theta)\right)$ \\
$\pi_{M}^{r *}$ & $\left(\theta(-s+\alpha)\left(\eta-c_{n}\right)+(s(-1+2 \theta)+\beta)\left(s+\eta \theta-c_{g}\right)\right) /(4 \eta(-1+\theta)(-1+4 \theta))$ \\
\hline
\end{tabular}

TABLE 4: Price decision, sales volume, and profit of each member when the government subsidizes green product consumers.

\begin{tabular}{lc}
\hline Variable & Government subsidies are given to green product consumers \\
\hline$\omega_{n}^{c *}$ & $\left(\eta+c_{n}\right) / 2$ \\
$\omega_{g}^{c *}$ & $\left(s+\eta \theta+c_{g}\right) / 2$ \\
$p_{n}^{c *}$ & $\left(-s-2 \eta+5 \eta \theta+c_{g}+2 \theta c_{n}\right) /(-2+8 \theta)$ \\
$p_{g}^{c *}$ & $\left(-2 s+6 s \theta-3 \eta \theta+6 \eta \theta^{2}+2 \theta c_{g}+\theta c_{n}\right) /(-2+8 \theta)$ \\
$q_{n}^{c^{* *}}$ & $\theta(-s+\alpha) /(2 \eta(-1+\theta)(-1+4 \theta))$ \\
$q_{g}^{c *}$ & $(-s(1-2 \theta)+\beta) /(2 \eta(-1+\theta)(-1+4 \theta))$ \\
$\pi_{R 1}^{c *}$ & $\theta(-s+\alpha)^{2} /\left(4 \eta(1-4 \theta)^{2}(-1+\theta)\right)$ \\
$\pi_{R 2}^{c *}$ & $(-s(1-2 \theta)+\beta)^{2} /\left(4 \eta(1-4 \theta)^{2}(-1+\theta)\right)$ \\
$\pi_{M}^{c *}$ & $\left(\theta(-s+\alpha)\left(\eta-c_{n}\right)+(s(-1+2 \theta)+\beta)\left(s+\eta \theta-c_{g}\right)\right) /(4 \eta(-1+\theta)(-1+4 \theta))$ \\
\hline
\end{tabular}

products increases, that is, the government subsidies for green product consumers are also conducive to increasing the market share of green products. For general products, the impact of government subsidies on the price decisions and sales volume of general products is the same as in the scenario of government subsidized manufacturer and subsidized green product retailer.

Theorem 5. The comparison of wholesale price, sales price, sales volume, and profit under different government subsidy scenarios is as follows:

(1) $\omega_{n}^{o^{*}}=\omega_{n}^{m^{*}}=\omega_{n}^{r^{*}}=\omega_{n}^{c^{*}}$ and $\omega_{g}^{r^{*}}=\omega_{g}^{c^{*}}>\omega_{g}^{o^{*}}>\omega_{g}^{m^{*}}$

(2) $p_{n}^{o^{*}}>p_{n}^{m^{*}} 1 / n=p_{n}^{r^{*}}=p_{n}^{c^{*}}$ and $p_{g}^{c^{*}}>p_{g}^{o^{*}}>p_{n}^{m^{*}}=p_{n}^{r^{*}}$

(3) $q_{n}^{o^{*}}>q_{n}^{m^{*}}=q_{n}^{r^{*}}=q_{n}^{c^{*}}$ and $q_{g}^{m^{*}}=q_{g}^{r^{*}}=q_{g}^{c^{*}}>q_{g}^{o^{*}}$

(4) $\pi_{R 1}^{o^{*}}>\pi_{R 1}^{m^{*}}=\pi_{R 1}^{r^{*}}=\pi_{R 1}^{c^{*}}, \pi_{R 2}^{m^{*}}=\pi_{R 2}^{r^{*}}=\pi_{R 2}^{c^{*}}>\pi_{R 2}^{o^{*}}$, and $\pi_{M}^{m^{*}}=\pi_{M}^{r^{*}}=\pi_{M}^{c^{*}}>\pi_{M}^{o^{*}}$

(5) $\pi_{R 1}^{o^{*}}>\pi_{R 1}^{m^{*}}=\pi_{R 1}^{r^{*}}=\pi_{R 1}^{c^{*}}$ and $\pi_{R 2}^{m^{*}}=\pi_{R 2}^{r^{*}}=\pi_{R 2}^{c^{*}}>\pi_{R 2}^{o^{*}}$

(6) When $s>\max \{0, T\}, \pi_{M}^{m^{*}}=\pi_{M}^{r^{*}}=\pi_{M}^{c^{*}}>\pi_{M}^{o^{*}}$

Proof. See Appendix.

According to Theorem 5, by comparison, firstly, when the government subsidizes the manufacturer, the wholesale price and sales price of the green product are the smallest. When the government subsidizes green product consumers, the wholesale price and sales price of green products are the largest. When the government subsidizes the green product retailer, the wholesale price of green products is the same as when subsidies are given to green product consumers; the sales price of green products is the same as when subsidies are given to the manufacturer. Mainly because when the government subsidizes the manufacturer, the manufacturer shares government subsidies with the green product retailer by lowering wholesale prices, and the green product retailer shares government subsidies with green product consumers by lowering sales prices. When the government subsidizes green product consumers, the manufacturer and green product retailers share government subsidies by increasing wholesale prices and sales prices, respectively. When the government subsidizes the green product retailer, the manufacturer shares government subsidies by raising wholesale prices and green product retailers share government subsidies with consumers by lowering sales prices. Secondly, for the three subsidies, no matter what kind of subsidy the government adopts, the wholesale price, sales price, sales volume of the general products, the sales volume of green products, and the profits of each enterprise remain unchanged. Thirdly, the wholesale price of general products has not changed before and after subsidies, and the sales price and sales volume are smaller than before the subsidy, indicating that government subsidies reduce the market demand for general products. In terms of corporate profits, the profit of the green product retailer is greater than that before subsidies, the profit of the general product retailer is less than the profit before subsidies; when $s>\max \{0, T\}$, the profit of the manufacturer is greater than the profit before subsidies. These indicate that the government subsidies increase the profits of the green product retailer, while the profits of the general product retailer decreaseand the profit of the manufacturer depends on the quota of government subsidies.

\section{Numerical Example and Analysis}

In order to verify the effectiveness of the green supply chain price decision model based on consumer complexity under the scenarios of government subsidy to different objects, the following will further analyze and verify the relevant 
conclusions by assigning relevant parameters in the model. Based on the relevant parameter settings in the literature $[18,19]$, the parameters in the examples are assigned as follows: $c_{n}=1.5, c_{g}=2, \theta=1.16$, and $\eta=4$.

\subsection{Analysis of the Impact of Changes in Government Subsidy Quota on Product Prices under Different Government Subsidy Scenarios}

4.1.1. Analysis of the Impact of Changes in Government Subsidy Quota on Product Prices When Government Subsidizes the Manufacturer. As can be seen from Figure 2, when the government subsidizes the manufacturer, the wholesale price and sales price of the green product decrease with the increase of the government subsidy quota. The wholesale price of general products does not change with the change of subsidy quota; the sales price of general products decreases with the increase of government subsidies, and it can be seen from Figure 2 that as the subsidy quota continues to increase, the sales price of general products is gradually reduced, even close to the wholesale price.

4.1.2. Analysis of the Impact of Changes in Government Subsidy Quota on Product Prices When Government Subsidizes Green Product Retailer. When the government subsidizes the green product retailer, the impact of changes in government subsidy quota on product prices is shown in Figure 3. As can be seen from Figure 3, as the quota of subsidies increases, the wholesale price of green products gradually increases and the sales price gradually decreases. The wholesale price of general products does not change with the change of subsidy quota, and the sales price of general products decreases with the increase of government subsidies. Combined with Figure 3 and related calculations, when the government subsidy quota meets $0<s<0.098$, the sales price of green products is greater than the wholesale price. When $0.098<s<0.5$, the sales price of green products is less than the wholesale price.

4.1.3. Analysis of the Impact of Changes in Government Subsidy Quota on Product Prices When Government Subsidizes Green Product Consumers. When the government subsidizes green product consumers, the impact of government subsidy quota changes on product prices is shown in Figure 4. As can be seen from Figure 4, as the quota of subsidies increases, the wholesale price and sales price of green products increases. The wholesale price of general products does not change with the change of subsidy quota, and the sales price of general products decreases with the increase of government subsidies.

\subsection{Analysis of the Impact of Changes in Government Subsidy} Quota on Product Sales Volume. Combined with the abovementioned analysis and Figure 5, it can be seen that, under the scenarios of government subsidized three different objects, changes in the government subsidy quota have the same effect on the sales volume of green products and

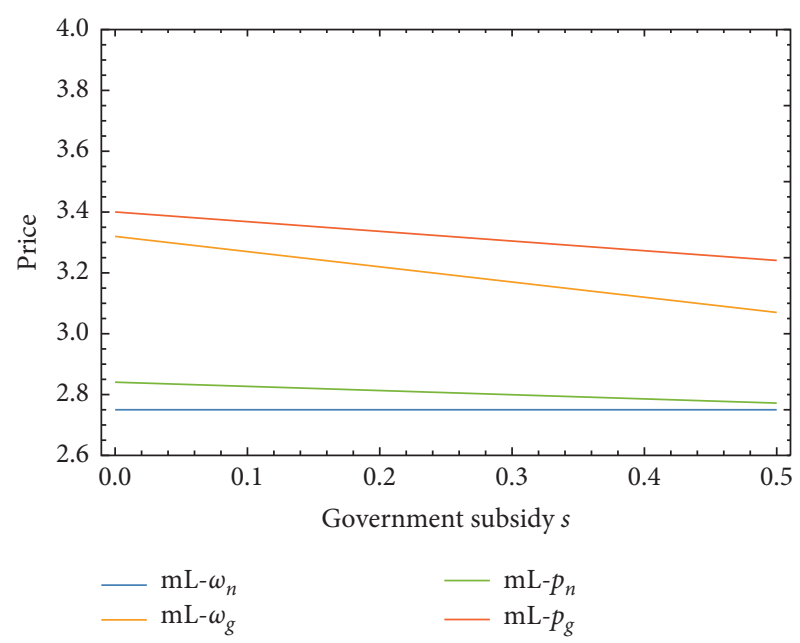

FIgURE 2: The impact of changes in government subsidies on product prices when government subsidizes the manufacturer.

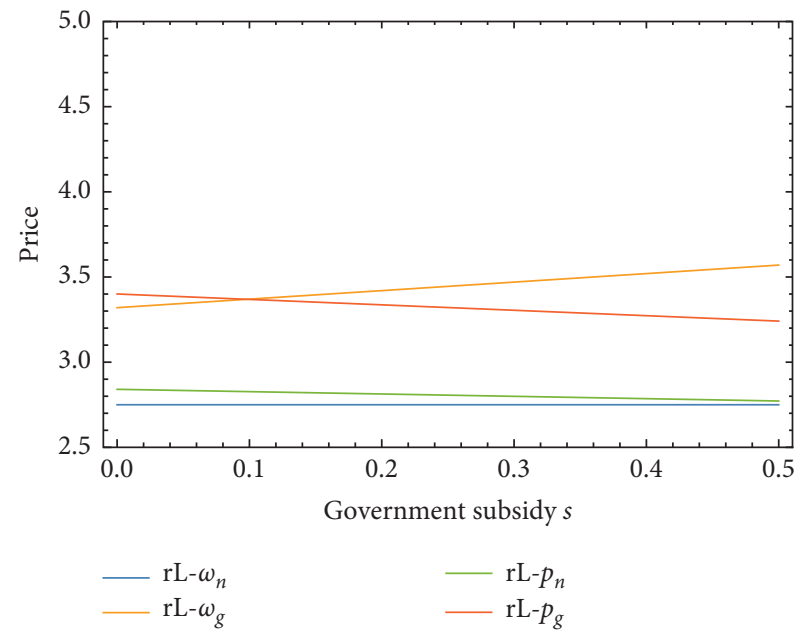

FIGURE 3: The impact of changes in government subsidies on product prices when government subsidizes the green product retailer.

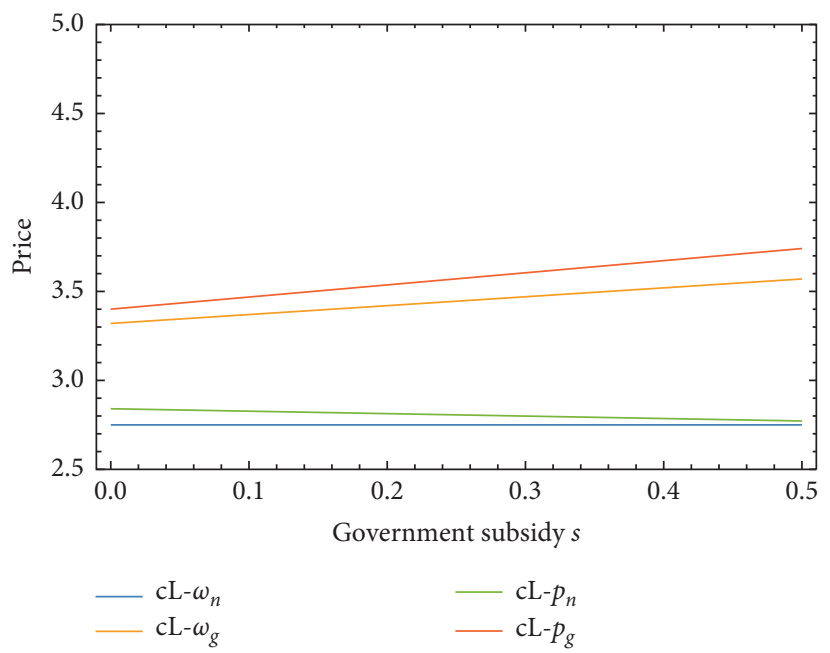

FIgURE 4: The impact of changes in government subsidies on product prices when government subsidizes green product consumers. 


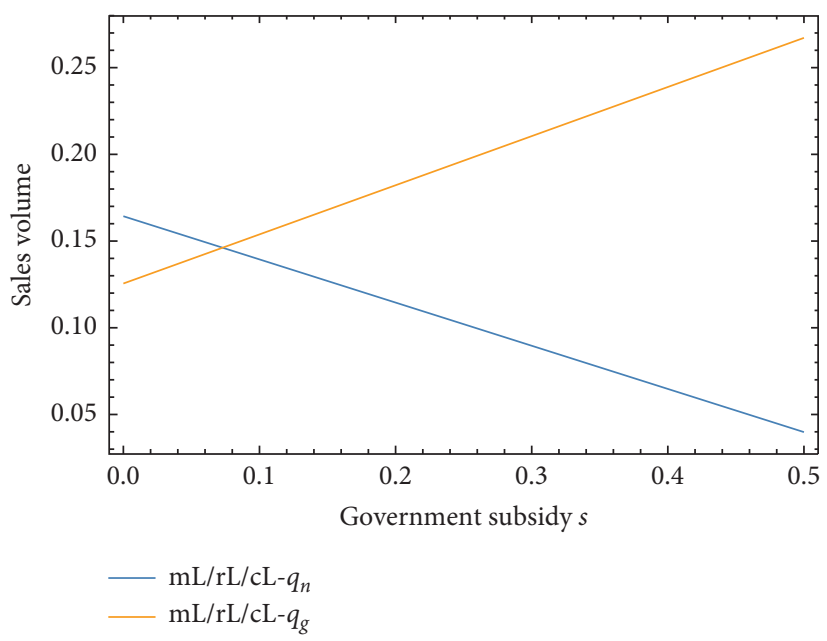

Figure 5: The impact of changes in government subsidies on product sales volume under the scenarios of government subsidizes three different objects.

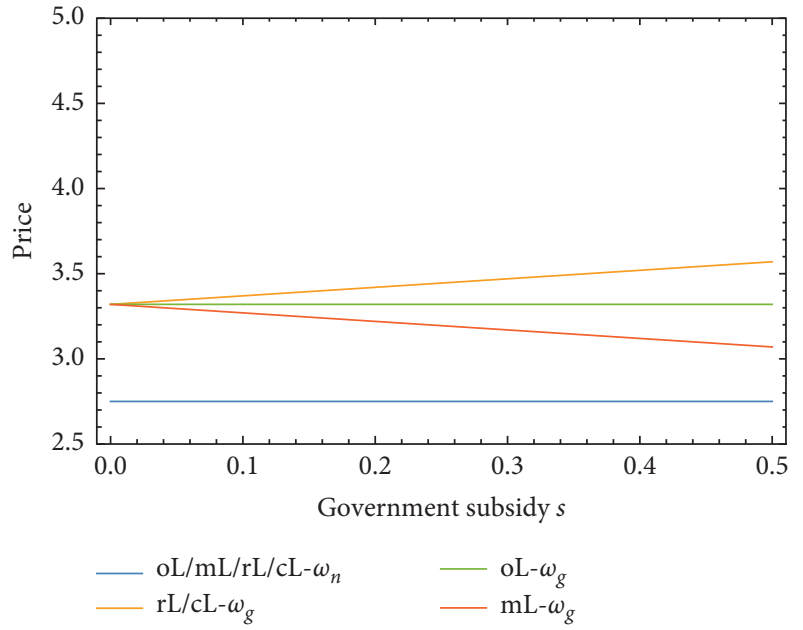

(a)

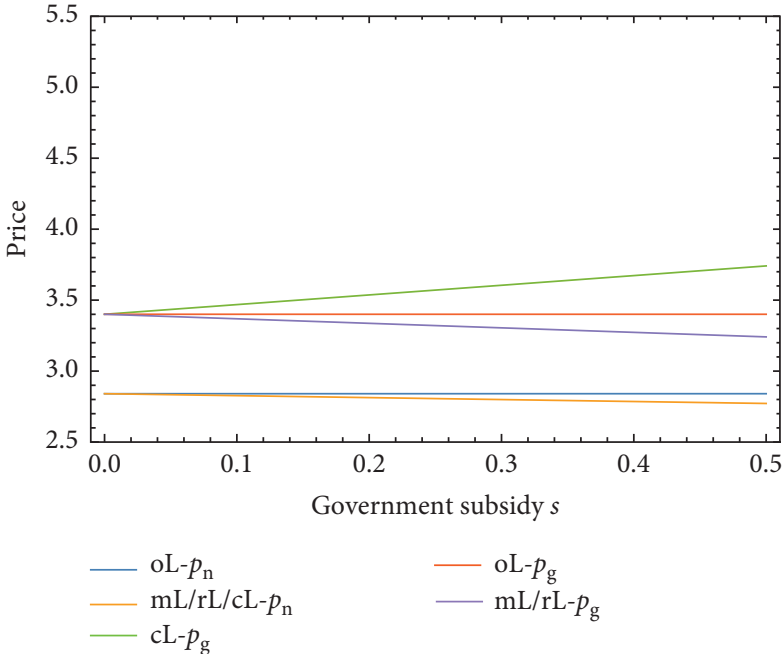

(b)

Figure 6: (a) Comparison of product wholesale prices and (b) comparison of product sales prices.

general products, that is, as can be seen from Figure 5, the sales volume of green products increases with the increase of government subsidies, and the sales volume of general products decreases with the increase of government subsidies.

\subsection{Comparative Analysis of Price, Sales Volume, and Profits under the Scenarios of Government Subsidies to Different Objects}

4.3.1. Comparison of Product Prices under Different Government Subsidy Scenarios. Figure 6(a) shows that the wholesale prices of general products are the same with or without government subsidies and are lower than those of green products, and the wholesale price of green products is the same and largest in the two scenarios of government subsidies to the green product retailer and green product consumers and is the smallest when government subsidies are given to the manufacturer. As can be seen from Figure 6(b), the sales price of general products is the same in the scenarios of government subsidized three different objects and is smaller than the sales price when there is no government subsidy.

4.3.2. Comparison of Product Sales Volume under Different Government Subsidy Scenarios. The comparison of product sales volume under different subsidy scenarios is shown in Figure 7. As can be seen from Figure 7, when there is no government subsidy, the sales volume of general products is always greater than the sales volume of green products, and the sales volume of general products is the same in the scenario of government subsidized three different objects 


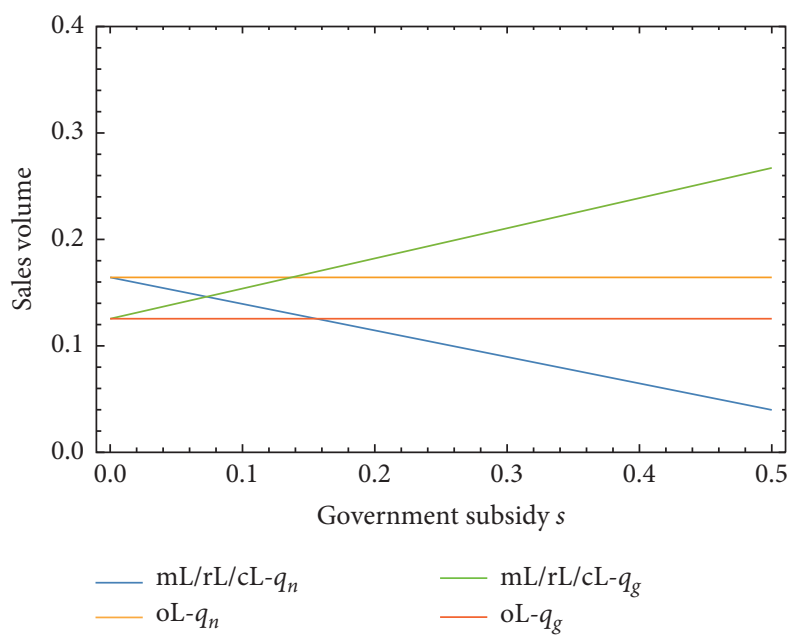

Figure 7: Comparison of product sales volume.

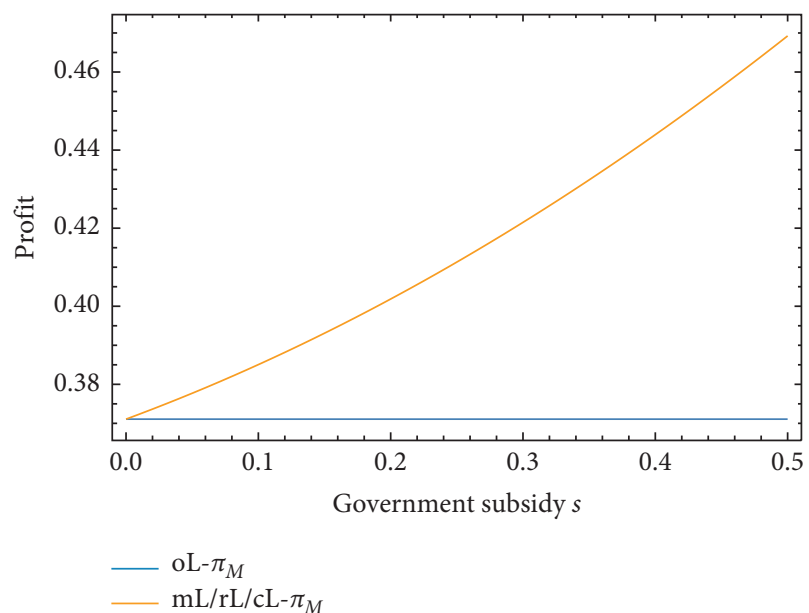

(a)

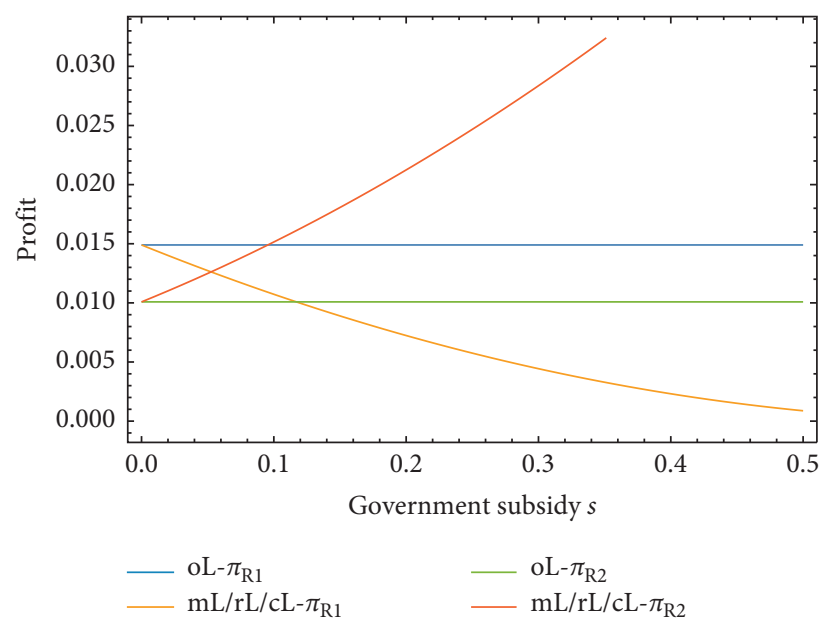

(b)

FIGURE 8: (a) Comparison of the manufacturer's profits and (b) comparison of retailer profits.

and is smaller than the sales volume when there is no government subsidy, and the sales volume of green products is the same in the scenario of government subsidized three different objects and is greater than the sales volume when there is no government subsidy. Combined with Figure 7 and related calculations, when the government subsidy quota meets $0<s<0.073$, the sales volume of green products is less than the sales volume of general products. When $0.073<s<0.5$, the sales volume of green products is greater than the sales volume of general products, indicating that a certain amount of government subsidies can promote the sales of green products and improve the market competitiveness of green products, thereby promoting the development of green supply chains.

4.3.3. Comparison of Profits under Different Government Subsidy Scenarios. It can be seen from the calculation that $T=-0.886$, and because $s>\max \{0, T\}$, so under the condition of $s \in[0,0.5]$ and as shown in Figure 8(a), the manufacturer's profit increases with the increase of government subsidies, and the profit of the manufacturer is the same in the scenario of government subsidized three different objects and is greater than the sales volume when there is no government subsidy. It can be seen from Figure $8(\mathrm{~b})$ that, in the scenario of no government subsidy, the profit of the general product retailer is greater than the profit of the green product retailer, the profit of the general product retailer is the same in the scenario of government subsidized three different objects, and the profit of the green product retailer is the same in the scenario of government subsidized three different objects. However, as the quota of subsidies continues to increase, the profit of the general product retailer is decreasing, and the profit of the green product retailer is increasing. When $0.05<s<0.5$, the profit of the green product retailer is greater than the profit of the general product retailer. 


\section{Conclusions}

This paper constructs a two-stage game model composed of the manufacturer, general product retailer, and green product retailer. Based on the complexity characteristics of the consumer group, this paper studies the impact of government subsidized different objects on price decisions of members in the green supply chain, compares the product price decision-making, sales volume and profit under different subsidy scenarios, and discusses the effectiveness of the model in combination with numerical analysis.

The research results show that firstly, compared with the no government subsidies; when the government subsidizes the manufacturer, the wholesale price and sales price of green products are reduced; when the government subsidizes the green product retailer, it will lead to an increase in the wholesale price of green products and a decrease in sales prices; when the government subsidizes green product consumers, the wholesale price and sales price of green products are increased. In the scenario of the government subsidized three main objects, the wholesale prices of general products do not change and the sales prices of general products will decrease. Secondly, regardless of which object the government subsidizes, the sales volume of green products will increase compared with the nongovernment subsidies, and the sales volume of general products will decrease, indicating that government subsidies can promote the sales of green products and suppress the sales of general products, thereby expanding the market share of green products. Thirdly, the three kinds of subsidies of government subsidized manufacturer, green product retailer, and green product consumers have the same effect on corporate profits. Compared with nongovernment subsidies, government subsidies increase the profit of the green product retailer and reduce the profit of the general product retailer, while the impact on the manufacturer's profit is related to the quota of government subsidies.

This study proposes the following recommendations. Firstly, when formulating a green industry development strategy, the government should strengthen the publicity and education of the green economy, raise consumers' awareness of environmental protection, and increase the level of consumer consumption by adopting some measures to improve national income. Secondly, the government should provide financial support for the development of the green supply chain through subsidy policies, encourage enterprises to carry out technological innovation, reduce the production cost of green products, and thus expand the market share of green products. Finally, enterprises should continuously improve the level of green production technology, as far as possible to reduce pollution to the environment.

\section{Appendix}

Proof of Lemma 1. Firstly, substituting equations (3) and (4) into equations (6) and (7), respectively, yields $\pi_{R 1}^{o}=\left(p_{n}^{o}-\right.$ $\left.\omega_{n}^{o}\right) p_{g}^{o}-\theta p_{n}^{o} / \eta(\theta-1) \quad$ and $\quad \pi_{R 2}^{o}=\left(p_{g}^{o}-\omega_{g}^{o}\right) \eta(\theta-1)-$ $\left(p_{g}^{o}-p_{n}^{o}\right) / \eta(\theta-1)$, and because of $\theta>1, \eta>1$; it can be seen that $\pi_{R 1}^{o}$ and $\pi_{R 2}^{o}$ are functions of the parabola of the variables $p_{n}^{o}$ and $p_{g}^{o}$, respectively, so it can be concluded that $\pi_{R 1}^{o}$ is a concave function about the variable $p_{n}^{o}$, and $\pi_{R 2}^{o}$ is a concave function about the variable $p_{g}^{o}$.

Secondly, equations (6) and (7) are solved to obtain $p_{n}^{o}=$ $\omega_{g}^{o}+2 \theta \omega_{n}^{o}+\eta(\theta-1) /(4 \theta-1) \quad$ and $\quad p_{g}^{o}=2 \theta \omega_{g}^{o}+\theta \omega_{n}^{o}+$ $2 \theta \eta(\theta-1) /(4 \theta-1)$, and equations (3) and (4), and $p_{n}^{o}$ and $p_{g}^{o}$ are substituted into equation (5) to obtain

$$
\begin{aligned}
\pi_{M}^{o}= & \left(\omega_{n}^{o}-c_{n}\right)\left(\frac{2 \theta \omega_{g}^{o}+\theta \omega_{n}^{o}+2 \theta \eta(\theta-1)}{\eta(\theta-1)(4 \theta-1)}+\theta \frac{-\omega_{g}^{o}-2 \theta \omega_{n}^{o}-\eta(\theta-1)}{\eta(\theta-1)(4 \theta-1)}\right) \\
& +\left(\omega_{g}^{o}-c_{g}\right)\left(1-\frac{2 \theta \omega_{g}^{o}+\theta \omega_{n}^{o}+2 \theta \eta(\theta-1)}{\eta(\theta-1)(4 \theta-1)}+\frac{-\omega_{g}^{o}-2 \theta \omega_{n}^{o}-\eta(\theta-1)}{\eta(\theta-1)(4 \theta-1)}\right) .
\end{aligned}
$$

By solving the second-order partial derivative of $\omega_{n}^{\mathrm{o}}$ and $\omega_{g}^{\mathrm{o}}$ for this equation, we can obtain the Hessian Matrix about $\omega_{n}^{\mathrm{O}}$ and $\omega_{g}^{\mathrm{o}}$ :

$\left[\begin{array}{cc}\frac{\partial^{2} \pi_{M}^{o}}{\partial \omega_{n}^{o} 2} & \frac{\partial^{2} \pi_{M}^{o}}{\partial \omega_{n}^{o} \partial \omega_{g}^{o}} \\ \frac{\partial^{2} \pi_{M}^{o}}{\partial \omega_{g}^{o} \partial \omega_{n}^{o}} & \frac{\partial^{2} \pi_{M}^{o}}{\partial \omega_{g}^{o}}\end{array}\right]=\left[\begin{array}{ll}\frac{2 \theta(1-2 \theta)}{\eta(1-4 \theta)(1-\theta)} & \frac{2 \theta}{\eta(1-4 \theta)(1-\theta)} \\ \frac{2 \theta}{\eta(1-4 \theta)(1-\theta)} & \frac{2-4 \theta}{\eta(1-4 \theta)(1-\theta)}\end{array}\right]<0$.

Therefore, equation (5) is a concave function with respect to $\omega_{n}^{o}$ and $\omega_{g}^{o}$.
Proof of Theorem 1.

(1) The condition that there is no green product in the market is $q_{g}^{o^{*}} \leq 0$ so that $-2 \eta \theta+2 \eta \theta^{2}+(1-2 \theta) c_{g}+$ $\theta c_{n} \leq 0$ is obtained, that is, $\eta \leq \theta c_{n}+$ $(1-2 \theta) c_{g} / 2 \theta(1-\theta)$, and because of $\eta>1$, one can obtain $1<\eta \leq \theta c_{n}+(1-2 \theta) c_{g} / 2 \theta(1-\theta)$, that is, $1<\eta \leq X$.

(2) When there are general products and green products in the market, since the green products are still in the initial stage of development, therefore, $0<q_{g}^{o^{*}}<q_{n}^{o^{*}}$ is assumed, $\quad q_{a}^{o^{*}}>0$ is solved, and $\eta>\theta c_{n}+$ $(1-2 \theta) c_{g} / 2 \theta(1-\theta)$ is obtained. From $q_{g}^{o^{*}}>q_{n}^{o^{*}}$, one can obtain $\theta\left(-\eta(1-\theta)+c_{g}+(1-2 \theta) \quad c_{n}\right)-$ 
$\left(-2 \eta \theta(1-\theta)+(1-2 \theta) c_{g}+\theta c_{n}\right)>0 ;$ then, $\eta<2 \theta^{2}$ $c_{n}+(1-3 \theta) c_{g} / 2 \theta(1-\theta)$ is obtained, so $\theta c_{n}+(1-$ $2 \theta) c_{g} / 2 \theta(1-\theta)<\eta<2 \theta^{2} c_{n}+(1-3 \theta) c_{g} / \theta(1-\quad \theta)$, that is, $X<\eta<Y$.

Proof of Theorem 2. The first-order partial derivative of the wholesale price, sales price, and sales volume of the general product and the green product with respect to the subsidy quota $s$ can be obtained:

$$
\begin{aligned}
& \text { (1) }\left(\partial \omega_{n}^{m *} / \partial s\right)=0 \\
& \text { (2) }\left(\partial \omega_{g}^{m *} / \partial s\right)=(1 / 2)>0 \\
& \text { (3) }\left(\partial p_{n}^{m *} / \partial s\right)=-(1 /(-2+8 \theta))<0 \\
& \text { (4) }\left(\partial p_{g}^{m *} / \partial s\right)=(-\theta /-1+4 \theta)<0 \\
& \text { (5) }\left(\partial q_{n}^{m *} / \partial s\right)=(-\theta / 2 \eta(-1+\theta)(-1+4 \theta))<0 \\
& \text { (6) }\left(\partial q_{g}^{m *} / \partial s\right)=\left(-1+2 \theta / 2 \eta\left(1-5 \theta+4 \theta^{2}\right)\right)>0
\end{aligned}
$$

Proof of Theorem 3. The first-order partial derivative of the wholesale price, sales price, and sales volume of the general product and the green product with respect to the subsidy quota $s$ can be obtained:

$$
\begin{aligned}
& \text { (1) }\left(\partial \omega_{n}^{r *} / \partial s\right)=0 \\
& \text { (2) }\left(\partial \omega_{g}^{r *} / \partial s\right)=(1 / 2)>0 \\
& \text { (3) }\left(\partial p_{n}^{r *} / \partial s\right)=(-1 /(-2+8 \theta))<0 \\
& \text { (4) }\left(\partial p_{g}^{r *} / \partial s\right)=(-\theta /(-1+4 \theta))<0 \\
& \text { (5) }\left(\partial q_{n}^{r *} / \partial s\right)=(-\theta / 2 \eta(-1+\theta)(-1+4 \theta))<0 \\
& \text { (6) }\left(\partial q_{g}^{r *} / \partial s\right)=\left(-1+2 \theta / 2 \eta\left(1-5 \theta+4 \theta^{2}\right)\right)>0
\end{aligned}
$$

Proof of Theorem 4. The first-order partial derivative of the wholesale price, sales price, and sales volume of the general product and the green product with respect to the subsidy quota $s$ can be obtained:

$$
\begin{aligned}
& \text { (1) }\left(\partial \omega_{n}^{c *} / \partial s\right)=0 \\
& \text { (2) }\left(\partial \omega_{g}^{c *} / \partial s\right)=(1 / 2)>0 \\
& \text { (3) }\left(\partial p_{n}^{c *} / \partial s\right)=(-1 /-2+8 \theta)<0 \\
& \text { (4) }\left(\partial p_{g}^{c *} / \partial s\right)=((-1+3 \theta) /(-1+4 \theta))>0 \\
& \text { (5) }\left(\partial q_{n}^{c *} / \partial s\right)=(-\theta / 2 \eta(-1+\theta)(-1+4 \theta))<0 \\
& \text { (6) }\left(\partial q_{g}^{c^{*}} / \partial s\right)=\left((-1+2 \theta) / 2 \eta\left(1-5 \theta+4 \theta^{2}\right)\right)>0
\end{aligned}
$$

Proof of Theorem 5. (1) From $\omega_{n}^{o^{*}}-\omega_{n}^{m^{*}}=\omega_{n}^{m^{*}}-$ $\omega_{n_{*}}^{r^{*}}=\omega_{n}^{r^{*}}-\omega_{n}^{c^{*}}=\omega_{n}^{c^{*}}-\omega_{n}^{o^{*}}=0$, one can obtain $\omega_{n^{*}}^{o^{*}}=\omega_{n}^{m^{*}}=\omega_{n}^{r^{*}}=\omega_{n}^{c^{*}}$. $\quad$ From $\quad \omega_{g}^{r^{*}}-\omega_{g}^{c^{*}}=0, \quad \omega_{g}^{c^{*}}-$ $\omega_{g}^{o^{*}}=(1 / 2) s, \omega_{g}^{c^{*}}-\omega_{g}^{m^{*}}=s$, and $\omega_{g}^{o^{*}}-\omega_{g}^{m^{*}} \stackrel{g}{=}(1 / 2) s$; therefore, $\omega_{g}^{r^{*}}=\omega_{g}^{c^{*}}>\omega_{g}^{o^{*}}>\omega_{g}^{m^{*}}$ can be obtained, the same can be proved in (2), (3), and (4).

(5) From $\pi_{M}^{m^{*}}-\pi_{M}^{r^{*}}=0, \pi_{M}^{m^{*}}-\pi_{M}^{c^{*}}=0, \pi_{M}^{r^{*}}-\pi_{M}^{c^{*}}=0$, one can obtain $\pi_{M}^{m^{*}}=\pi_{M}^{r^{*}}=\pi_{M}^{c^{*}}$. When $s>T$, one can know that $\pi_{M}^{m^{*}}-\pi_{M}^{o^{*}}=\left(s\left(s(-1+2 \theta)+2(1-2 \theta) c_{g}+2 \theta c_{n}+4 \eta \theta\right.\right.$ $(-1+\theta)) / 4 \eta(-1+\theta)(-1+4 \theta))>0$, and one can obtain $\pi_{M}^{m^{*}}>\pi_{M}^{o^{*}}$; then, $s>\max \{0, T\}$ can be obtained, and $\pi_{M}^{m^{*}}=\pi_{M}^{r^{*}}=\pi_{M}^{c^{*}}>\pi_{M}^{o^{*}}$.

\section{Data Availability}

The data used to support the findings of this study are available from the corresponding author upon request.

\section{Conflicts of Interest}

The authors declare that there are no conflicts of interest regarding the publication of this paper.

\section{Acknowledgments}

This work was supported by the National Natural Science Foundation of China (nos. 71971100, 71671078, and 71501084); Social Science Fund of Jiangsu Province (nos. 19GLB005 and 19GLB018); The Key Project of Philosophy and Social Science Research in Colleges and Universities in Jiangsu Province (no. 2018SJZDI052); and The National Social Science Fund of China (no. 18VSJ038), and sponsored by Qing Lan Project of Jiangsu Province; Youth Backbone Teacher Training Project of Jiangsu University.

\section{References}

[1] U. R. de Oliveira, L. S. Espindola, I. R. da Silva, I. N. da Silva, and H. M. Rocha, "A systematic literature review on green supply chain management: research implications and future perspectives," Journal of Cleaner Production, vol. 187, pp. 537-561, 2018.

[2] G. Bi, M. Jin, L. Ling, and F. Yang, "Environmental subsidy and the choice of green technology in the presence of green consumers," Annals of Operations Research, vol. 255, no. 1, pp. 1-22, 2017.

[3] W. Zhou and W. Huang, "Contract designs for energy-saving product development in a monopoly," European Journal of Operational Research, vol. 250, no. 3, pp. 902-913, 2016.

[4] D. Yang and T. Xiao, "Pricing and green level decisions of a green supply chain with governmental interventions under fuzzy uncertainties," Journal of Cleaner Production, vol. 149, pp. 1174-1187, 2017.

[5] J. Xue, R. Gong, L. Zhao, X. Ji, and Y. Xu, "A green supplychain decision model for energy-saving products that accounts for government subsidies," Sustainability, vol. 11, no. 8, p. 2209, 2019.

[6] H. Zhuo and S. Wei, "Gaming of green supply chain members under government subsidies-based on the perspective of demand uncertainty," Advances in Intelligent Systems and Computing, vol. 502, pp. 1105-1116, 2017.

[7] S. Zhan, Z. Shu, and H. Jiang, "Research on two-echelon green supply chain decision under government subsidy," American Journal of Industrial and Business Management, vol. 8, no. 3, pp. 487-495, 2018.

[8] Y. Yu, X. Han, and G. Hu, "Optimal production for manufacturers considering consumer environmental awareness and green subsidies," International Journal of Production Economics, vol. 182, pp. 397-408, 2016.

[9] D. Guo, Y. He, Y. Wu, and Q. Xu, "Analysis of supply chain under different subsidy policies of the government," Sustainability, vol. 8, no. 12, p. 1290, 2016.

[10] J. Chemama, M. C. Cohen, R. Lobel, and G. Perakis, "Consumer subsidies with a strategic supplier: commitment vs. flexibility," Management Science, vol. 65, no. 2, pp. 681-713, 2019. 
[11] M. C. Cohen, R. Lobel, and G. Perakis, "The impact of demand uncertainty on consumer subsidies for green technology adoption," Social Science Electronic Publishing, vol. 62, no. 4, pp. 868-878, 2015.

[12] P. He, Y. He, and H. Xu, "Channel structure and pricing in a dual-channel closed-loop supply chain with government subsidy," International Journal of Production Economics, vol. 213, pp. 108-123, 2019.

[13] J. Huang, M. Leng, L. Liang, and J. Liu, "Promoting electric automobiles: supply chain analysis under a government's subsidy incentive scheme," IIE Transactions, vol. 45, no. 8, pp. 826-844, 2013.

[14] B. Li, W. Chen, C. Xu, and P. Hou, "Impacts of government subsidies for environmental-friendly products in a dualchannel supply chain," Journal of Cleaner Production, vol. 171, pp. 1558-1576, 2018.

[15] W.-M. Ma, Z. Zhao, and H. Ke, "Dual-channel closed-loop supply chain with government consumption-subsidy," European Journal of Operational Research, vol. 226, no. 2, pp. 221-227, 2013.

[16] Y. L. Zhang, X. J. Hu, H. H. Yang, and C. D. Lu, "Green supply chain decision model based on government subsidies and consumer strategic behaviors," Forecasting, vol. 36, no. 2, pp. 57-63, 2017, in Chinese.

[17] W. Yan, Y. Xiong, Z. Xiong, and N. Guo, "Bricks vs. clicks: which is better for marketing remanufactured products?" European Journal of Operational Research, vol. 242, no. 2, pp. 434-444, 2015.

[18] F. X. Cheng, H. Q. Shao, and F. X. Ma, "Pricing decision of closed-loop supply chain considering consumers green preference under differential weight subsidy," Industrial Engineering and Management, vol. 24, no. 1, pp.111-118, 2019, in Chinese.

[19] Y. H. Tian and Q. H. Zhu, "Game model for diffusion of green supply chain management based on price subsidies of the government," Journal of Systems Engineering, vol. 31, no. 4, pp. 526-535, 2016, in Chinese. 